\title{
Use of recycled FRP reinforcing bar in concrete as coarse aggregate and its impact on the mechanical properties of concrete
}

\author{
Ardavan Yazdanbakhsh*, Lawrence C. Bank, and Chen Chen \\ Civil Engineering Department, City College of New York, New York, NY 10031, USA
}

Abstract. The production of fiber reinforced polymer (FRP) composite materials is a major source of non-degradable waste. The use of FRP bars for reinforcing concrete is increasing in construction. This study investigates the impact of replacing coarse natural aggregate (NA) in concrete with cut FRP bar waste (FRP-RA) on the compressive and tensile strength of both high strength and normal strength concretes. Concrete cylinders without any FRP-RA, with $40 \%$ of NA (the large-grade particles) replaced with FRP-RA, and 100\% replacement ratios of natural aggregate with equivalently graded FRP-RA were tested. The results show that the effect of the FRP-RA on the mentioned mechanical properties depends on the concrete strength, replacement ratio and the gradation-size of the NAs replaced. High-strength concrete performed better than low strength concrete and replacement of larger sized NA with FRP-RA resulted in better performance compared to full replacement. The test results show that existing empirical models can sometimes overestimate the tensile strength of lower-strength FRP-RA concretes. The findings show that although the use of FRP waste in concrete reduces the strength, concrete with structural grade mechanical properties can be produced with FRP-RA. The potential durability issues of FRP-RA concrete are discussed and future studies on this topic is proposed.

Keywords: Compressive Strength, Concrete, Rebar, Recycled aggregate, Recycled FRP, Tensile Strength.

\footnotetext{
* Corresponding author. Tel.: +1-212-650-6569; Fax: +1-212-650-6965. E-Mail: ayazdanbakhsh@ccny.cuny.edu
} 


\section{Introduction}

Fiber-reinforced polymer (FRP) composite materials have been used extensively in major industries including aerospace, marine, sporting goods and construction for over half a century [1]. The increased production of FRP materials has led to a significant increase in FRP scrap from production and end-of-life waste. Several methods exist for recycling FRP waste [2]. Hightech users of FRP materials, particularly aircraft manufacturers, have been investigating and implementing new recycling techniques [3]. The use of recycled FRP in concrete materials has been studied by a number of investigators [2, 4]. Most of the existing methods for recycling FRP waste are energy-intensive and may also involve the use of potentially costly or environmentallyharmful chemical and thermal processes (e.g., grinding FRP into powder to be used as filler in new materials, incinerating into ash). A less environmentally-negative and more economical FRP waste management approach is desirable. Cutting FRP waste into larger, coarse-aggregate-size particles than grinding or incinerating them may be a method with some potential. The scope of the present study is on mechanical properties of concrete with such FRP aggregates. Very limited research has been conducted on the use of FRP waste as coarse aggregate in concrete [5, 6]. The present work investigates mechanical properties of concrete incorporating commerciallyproduced FRP reinforcing bar (rebar) waste cut into aggregate-sized pieces.

This study focuses on two of the key mechanical properties of portland cement concrete, namely compressive strength and tensile strength. The compressive strength is the most frequently-used property of concrete in the design of reinforced concrete members. The tensile strength of concrete is also used in a number of design procedures, typically for serviceability based designs. This paper presents an experimental program designed to investigate the impact of partial and full replacement of coarse crushed stone (in this work referred to as coarse natural 
aggregate or NA) with similarly graded pieces of FRP waste (FRP-RA) on compressive and splitting tensile strength of concrete.

\section{Experimental program}

\subsection{Materials}

Waste from the production of helically-wrapped and sand-coated Aslan ${ }^{\mathrm{TM}}$ glass fiber reinforced polymer rebars produced by Hughes Brothers in the U.S. were used in this study. The manufacturer-reported properties of FRP rebars are presented in Table 1. Waste rebars with reported diameters of $6,10,13,16,19$, and $25 \mathrm{~mm}$ were removed from a pile of production scrap (Figure 1) and cut by using a diamond saw into short cylindrical pieces (Figure 2) with the same length as bar diameter (aspect ratio of one). The cut bars were proportioned to have the ASTM grading size of 56 (25.0 to $9.5 \mathrm{~mm}$ ) [7]. For each size number, ASTM defines maximum and minimum limits for different aggregate size sieve categories. The ASTM C33 No. 56 grading size distribution, which was specifically used for both NA and FRP-RA in this study, is presented in Table 2. To insure uniform aggregate size distribution for all mixes, aggregate particles retained on each sieve (with a standard opening size) were stored separately and were added to the concrete mix using the prescribed proportions presented in Table 2.

Table 3 shows the size gradations of FRP-RAs from cutting rebars with different sizes. The information in Table 3 was used to proportion cut rebars to achieve ASTM No. 56 FRP-RA. ASTM graded manufactured sand and Type I portland cement were used in all concrete mixes. 
Table 1. Manufacturer supplied properties of the FRP rebars

\begin{tabular}{l|l}
\hline Tensile strength, MPa & $620-896$ \\
\hline Transverse shear strength, MPa & 150 \\
\hline Tensile modulus of elasticity, GPa & 46 \\
\hline Specific gravity & 1.908 \\
\hline 24-hour moisture absorption, \% & $\leq 0.25$ \\
\hline Fiber content by weight, \% & 70 \\
\hline Fibers & ECR glass fibers \\
\hline Matrix material & Vinyl Ester resin \\
\hline
\end{tabular}

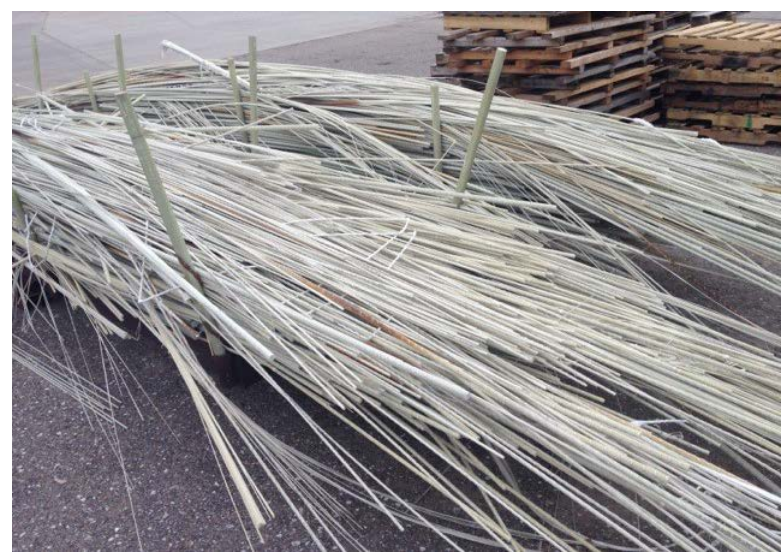

Figure 1. A pile of FRP rebar production scrap.

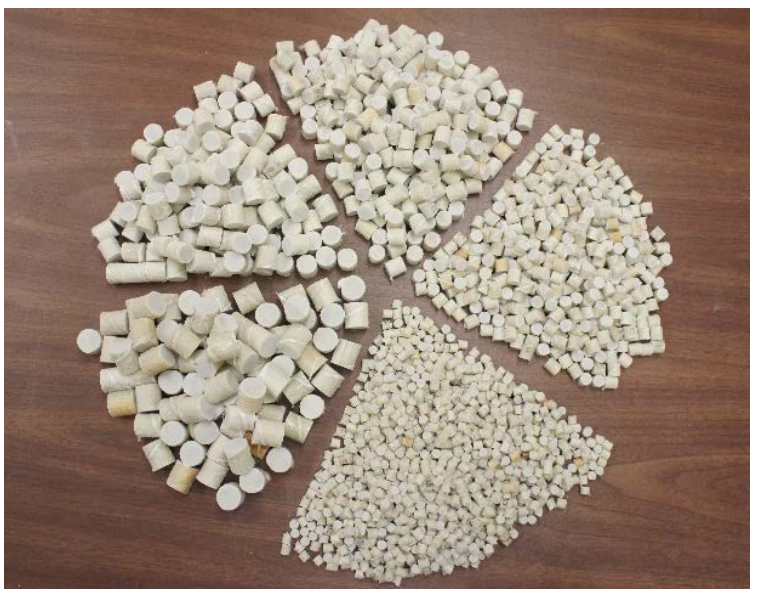

Figure 2. Some of the cut scrap FRP rebars (FRP-RA) used as coarse aggregate in the study. 
Table 2. Size gradation of coarse aggregate (both NA and FRP-RA) used in this study, according to ASTM C33, Size No. 56.

\begin{tabular}{|l|c|c|c|c|}
\hline \multicolumn{2}{|c|}{$\begin{array}{c}\text { Laboratory sieve } \\
\text { size }\end{array}$} & \multirow{2}{*}{$\begin{array}{c}\text { Agg. vol. finer } \\
\text { than sieve } \\
\text { opening, } \%\end{array}$} & \multicolumn{2}{c|}{$\begin{array}{c}\text { Agg. vol. retained } \\
\text { on sieve, \% }\end{array}$} \\
\cline { 1 - 1 } U.S. & mm & ASTM & $\begin{array}{c}\text { Used in } \\
\text { study }\end{array}$ \\
\hline $11 / 2$ in & 37.5 & 100 & 0 & 0.0 \\
\hline 1 in & 25.0 & $90-100$ & $0-10$ & 5.0 \\
\hline $3 / 4$ in & 19.0 & $40-85$ & $15-50$ & 35.0 \\
\hline $1 / 2$ in & 12.5 & $10-40$ & $30-45$ & 37.5 \\
\hline $3 / 8$ in & 9.5 & $0-15$ & $10-25$ & 17.5 \\
\hline No.4 & 4.8 & $0-5$ & $0-10$ & 5.0 \\
\hline No.8 & 2.4 & 0 & $0-5$ & 0.0 \\
\hline No.16 & 1.2 & 0 & 0 & 0.0 \\
\hline
\end{tabular}

Table 3. Size gradations (in terms of Vol \% retained on different sieves) of FRP-RAs produced from FRP rebars with different nominal diameters.

\begin{tabular}{c|c|c|c|c|c|c|c}
\hline \multicolumn{2}{c|}{ Sieve size } & \multicolumn{6}{c}{ Nominal diameter and height of cut rebars, in } \\
\hline U.S. & mm & 1 & $3 / 4$ & $5 / 8$ & $1 / 2$ & $3 / 8$ & $1 / 4$ \\
\hline 1 in & 25.0 & 100 & 0 & 0 & 0 & 0 & 0 \\
\hline $3 / 4$ in & 19.0 & 0 & 100 & 0 & 0 & 0 & 0 \\
\hline $1 / 2$ in & 12.5 & 0 & 0 & 100 & 100 & 0 & 0 \\
\hline $3 / 8$ in & 9.5 & 0 & 0 & 0 & 0 & 100 & 0 \\
\hline No. 4 & 4.8 & 0 & 0 & 0 & 0 & 0 & 100 \\
\hline No. 8 & 2.4 & 0 & 0 & 0 & 0 & 0 & 0 \\
\hline
\end{tabular}

\subsection{Specimen production and testing}

Two different concrete mixes were designed to have target compressive strength values of $40 \mathrm{MPa}$ and $50 \mathrm{MPa}$. The mixes are referred to as “N” and " $\mathrm{H}$ ”, for normal and high strength, respectively. For each concrete strength, three variations having different types of coarse 
aggregate were produced; control (N0 and H0), 40\% FRP-RA (large-sizes only) replacement (N40 and H40) and full FRP-RA replacement (N100 and H100). Mix proportions for all the variations are presented in Table 4. For the N40 and H40 mixes only the portion of NA aggregates retained on $19 \mathrm{~mm}$ and $25 \mathrm{~mm}$ sieves (40\% of total volume of coarse aggregate) were replaced with the same volume of FRP-RA obtained from cutting $19 \mathrm{~mm}$ and $25 \mathrm{~mm}$ rebars respectively. All the concrete mixes had a volumetric coarse aggregate content of close to $40 \%$. The amount of mixing water was adjusted based on the total moisture content and absorption capacities of natural fine and coarse aggregates. It was assumed that the moisture absorbed by oven-dry FRP-RAs during the first 20 minutes in water (the time required for mixing concrete and casting) is low. It was assumed that the rate of moisture absorption by FRP-RAs is slow, and the absorption characteristics of FRP-RAs were not used for adjusting the mixing water. After casting, the FRP-RAs (particularly their cut surfaces) absorb moisture from the surrounding mortar for several days or weeks. This may reduce the degree of hydration of cement particles adjacent to the FRP-RAs. It may also partially desiccate the capillary pores in the ITZ leading to local shrinkage and cracking. Both of these mechanisms can weaken the bond between FRP-RAs and the surrounding mortar. This hypothesis needs to be validated in a future study.

Table 4. Proportions of the concrete mixes.

\begin{tabular}{l|c|c|c|c|c}
\hline $\begin{array}{c}\text { Concrete } \\
\text { mix }\end{array}$ & $\begin{array}{c}\text { FRP-RA vol. } \\
\text { replacement } \\
\text { ratio, \% }\end{array}$ & $w / c$ & $\begin{array}{c}\text { Total agg. (coarse } \\
\text { and fine) } \\
\text { concrete vol. ratio }\end{array}$ & $\begin{array}{c}\text { Coarse agg./total } \\
\text { agg. vol. ratio }\end{array}$ & $\begin{array}{c}\text { Coarse agg./ } \\
\text { concrete vol. ratio }\end{array}$ \\
\hline $\mathrm{N} 0$ & 0 & 0.57 & 0.70 & 0.55 & 0.39 \\
\hline $\mathrm{N} 40$ & 40 & 0.57 & 0.70 & 0.55 & 0.39 \\
\hline $\mathrm{N} 100$ & 100 & 0.57 & 0.70 & 0.55 & 0.39 \\
\hline $\mathrm{H} 0$ & 0 & 0.44 & 0.60 & 0.67 & 0.40 \\
\hline $\mathrm{H} 40$ & 40 & 0.44 & 0.60 & 0.67 & 0.40 \\
\hline $\mathrm{H} 100$ & 100 & 0.44 & 0.60 & 0.67 & 0.40 \\
\hline
\end{tabular}



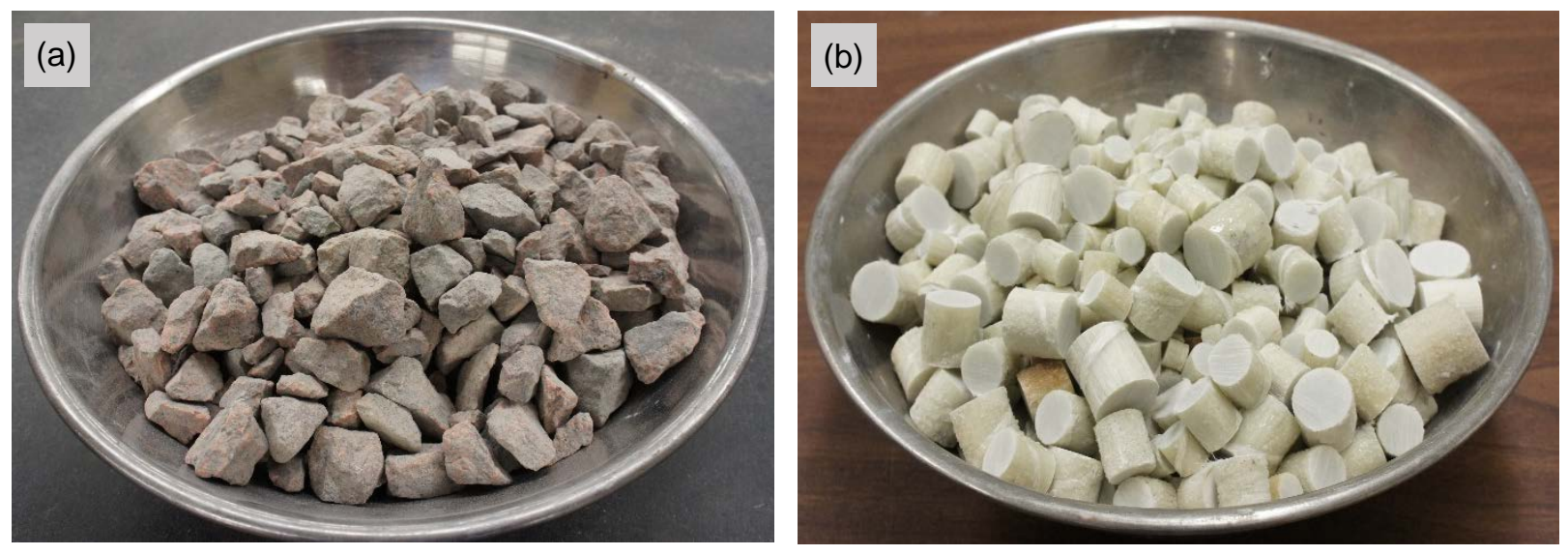

Figure 3. (a) NA used in control concrete mixes NO and HO, and (b) FRP-RA used in N100 and H100. The aggregates have the same size gradation (ASTM grading size number 56).

For each mix variation six $100 \mathrm{~mm}$ by $200 \mathrm{~mm}$ cylinders were produced. All the specimens were produced on the same day. The specimens were demolded after one day and transferred to an environmental chamber with RH of 98\%. 28 days after casting three specimens from each mix variation were tested for compressive strength (ASTM C39 [8]), and the three others were tested for splitting tensile strength (ASTM C496 [9]).

Theoretical values of splitting tensile strength $f_{c t, A C I}$ and $f_{c t, E C 2}$ presented by the ACI 318-14 (Section R19.2.4 [10]) and Eurocode 2 [11] were used to compare the splitting tensile strength test results with the values predicted by the models. According to ACI 318-14,

$f_{c t, A C I}=0.56 f_{c m}^{0.5}(\mathrm{MPa})$.

According to Eurocode 2:

$f_{c t, E C 2}=0.33 f_{c m}^{0.67}(\mathrm{MPa})$. 


\section{Test results}

Images of the failed compression and splitting specimens are shown in Figure 4 and Figure 5, respectively. The average compressive strength and the average splitting tensile strength of the concrete specimens for each of the mix variations and the predicted values of splitting tensile strength by the ACI model, $f_{c t, A C I}$, and Eurocode 2 model, $f_{c t, E C 2}$, (Eqns. 1 and 2, respectively) are presented in Table 5. The load-deflection data for the specimens tested in compression are shown in Figure 6 and Figure 7. The load-deflection data for the specimens tested in splitting tension are shown in Figure 8 and Figure 9. The curves were horizontally shifted to account for the initial flexibility of the neoprene pads used for testing [12]. 

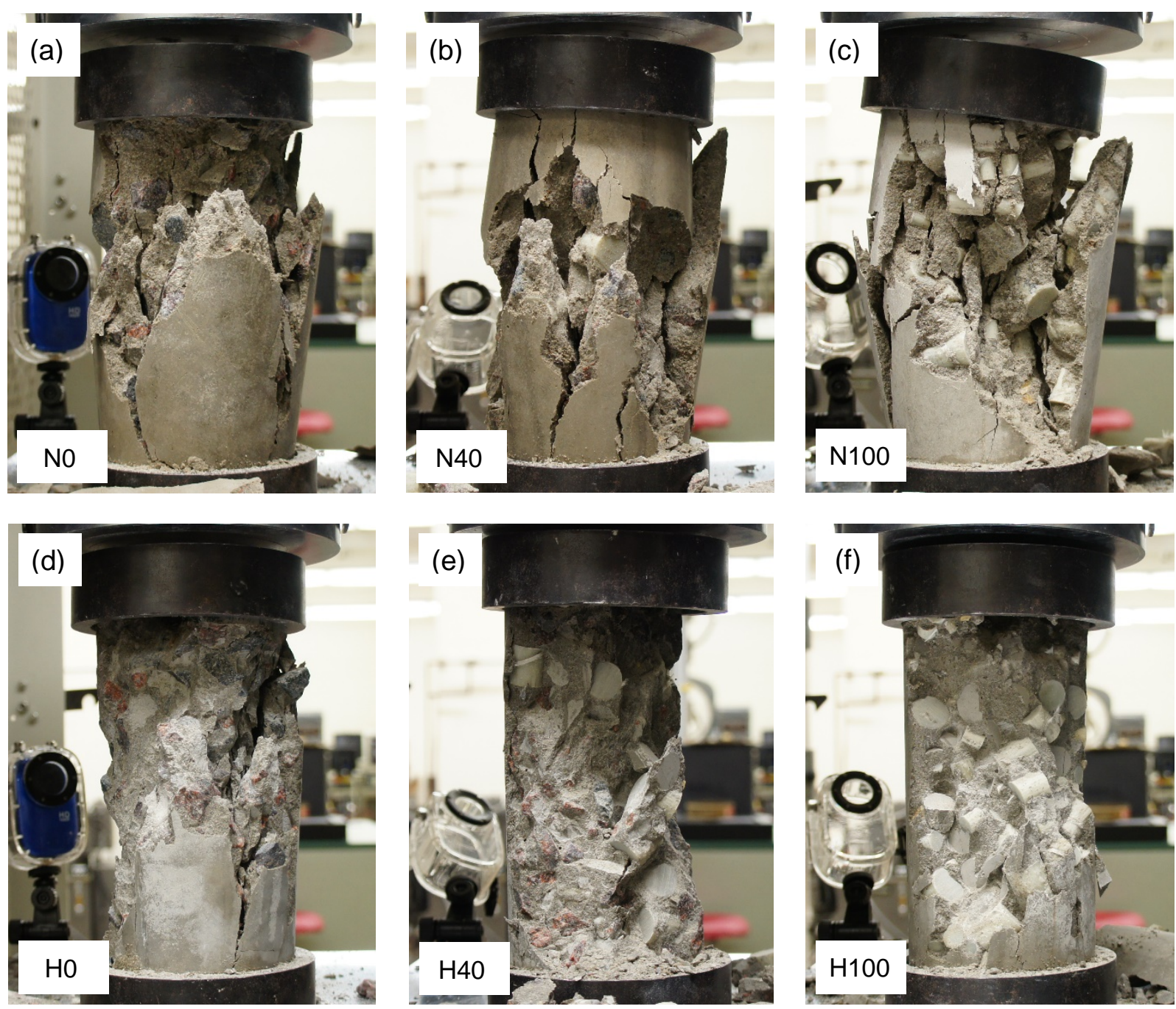

Figure 4. Examples of failed compressive test cylinder for each of the mixes 

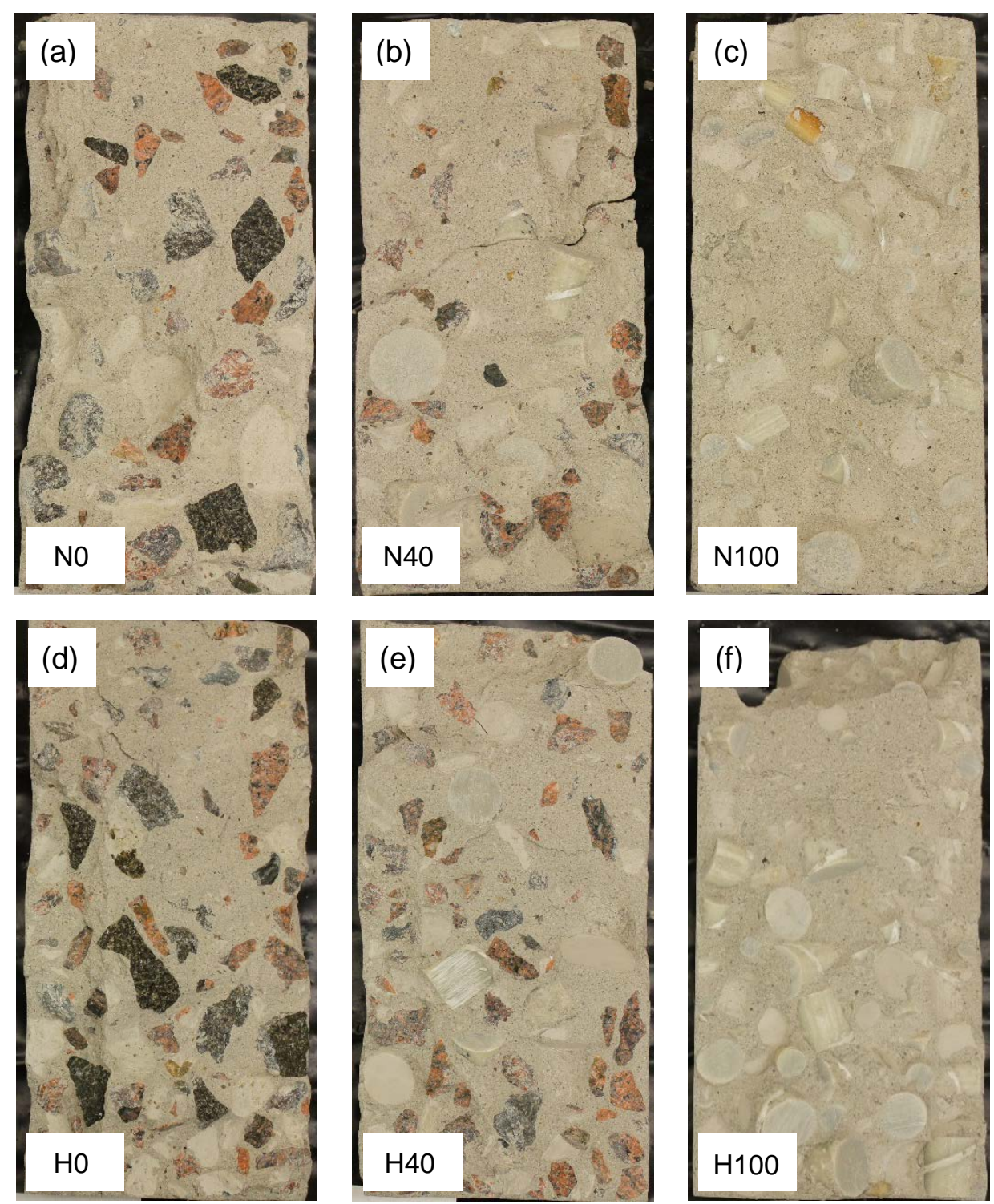

Figure 5. Examples of failed splitting test cylinders for each of the mixes 
Table 5. Compressive and splitting tensile strength values of different concrete mixes and the predicted values of splitting tensile strength by $\mathrm{ACl}$ model $\left(f_{c t, A C l}\right)$ and Eurocode 2 model $\left(f_{c t, E C 2}\right)$.

\begin{tabular}{|c|c|c|c|c|c|c|c|c|}
\hline Mix & $f_{c}^{\prime}, \mathrm{MPa}$ & $f_{c}^{\prime}$ (Avg) & $\%$ diff & $f_{c t}, \mathrm{MPa}$ & $f_{c t}(\mathrm{Avg})$ & $\%$ diff & $f_{c t, A C I}, \mathrm{MPa}$ & $f_{c t, E C 2}, \mathrm{MPa}$ \\
\hline \multirow{3}{*}{ No } & 35.6 & \multirow{3}{*}{37.5} & \multirow{3}{*}{-} & 3.7 & \multirow{3}{*}{4.0} & \multirow{3}{*}{-} & \multirow{3}{*}{3.4} & \multirow{3}{*}{3.7} \\
\hline & 39.0 & & & 4.3 & & & & \\
\hline & 38.0 & & & 4.1 & & & & \\
\hline \multirow{3}{*}{ N40 } & 32.5 & \multirow{3}{*}{32.8} & \multirow{3}{*}{13} & 2.7 & \multirow{3}{*}{3.0} & \multirow{3}{*}{26} & \multirow{3}{*}{3.2} & \multirow{3}{*}{3.4} \\
\hline & 33.2 & & & 2.8 & & & & \\
\hline & 32.6 & & & 3.4 & & & & \\
\hline \multirow{3}{*}{ N100 } & 30.5 & \multirow{3}{*}{29.5} & \multirow{3}{*}{21} & 2.8 & \multirow{3}{*}{2.6} & \multirow{3}{*}{35} & \multirow{3}{*}{3.0} & \multirow{3}{*}{3.2} \\
\hline & 29.3 & & & 2.6 & & & & \\
\hline & 28.8 & & & 2.5 & & & & \\
\hline \multirow{3}{*}{ HO } & 43.7 & \multirow{3}{*}{46.3} & \multirow{3}{*}{-} & 4.4 & \multirow{3}{*}{4.5} & \multirow{3}{*}{-} & \multirow{3}{*}{3.8} & \multirow{3}{*}{4.3} \\
\hline & $51.5^{*}$ & & & 4.3 & & & & \\
\hline & 48.8 & & & 4.8 & & & & \\
\hline \multirow{3}{*}{$\mathrm{H} 40$} & 42.9 & \multirow{3}{*}{40.4} & \multirow{3}{*}{13} & 3.8 & \multirow{3}{*}{4.0} & \multirow{3}{*}{12} & \multirow{3}{*}{3.6} & \multirow{3}{*}{3.9} \\
\hline & 40.3 & & & 3.8 & & & & \\
\hline & 38.0 & & & 4.3 & & & & \\
\hline & 39.5 & & & 3.6 & & & & \\
\hline H100 & 36.1 & 36.6 & 21 & 3.4 & 3.6 & 20 & 3.4 & 3.7 \\
\hline & 34.1 & & & 3.9 & & & & \\
\hline
\end{tabular}




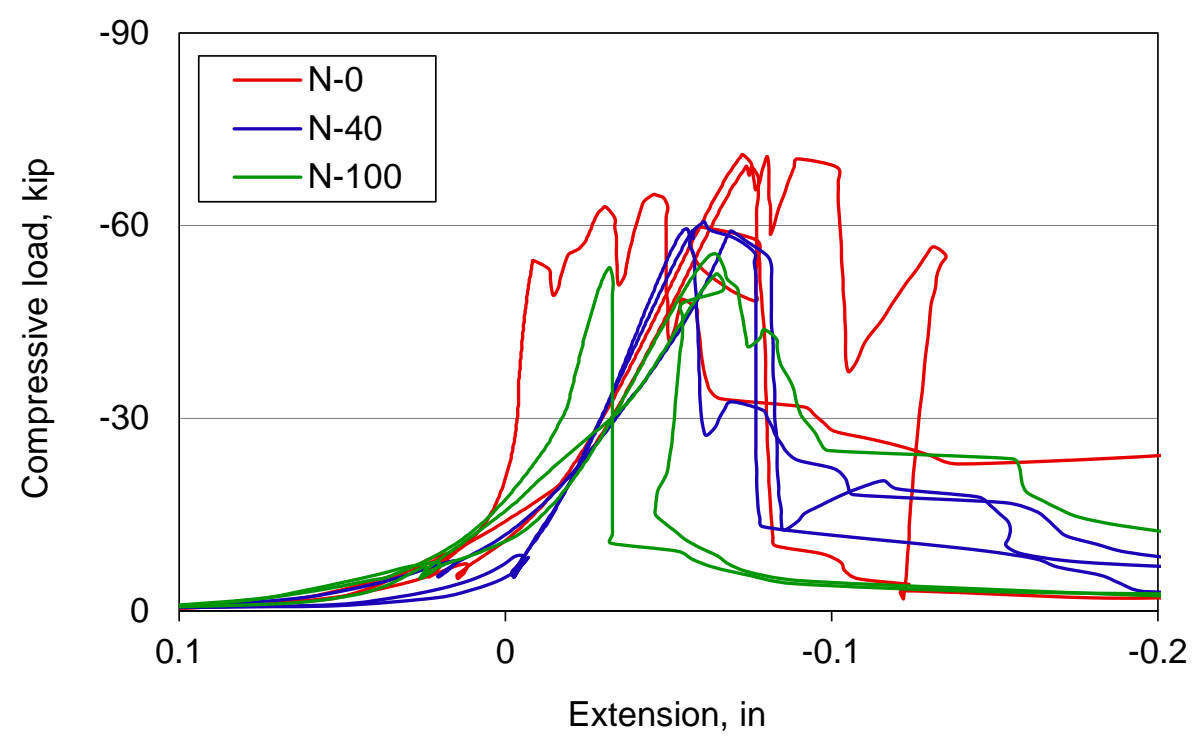

Figure 6. Load vs. displacement results for the compression testing of normal-strength concrete specimens.

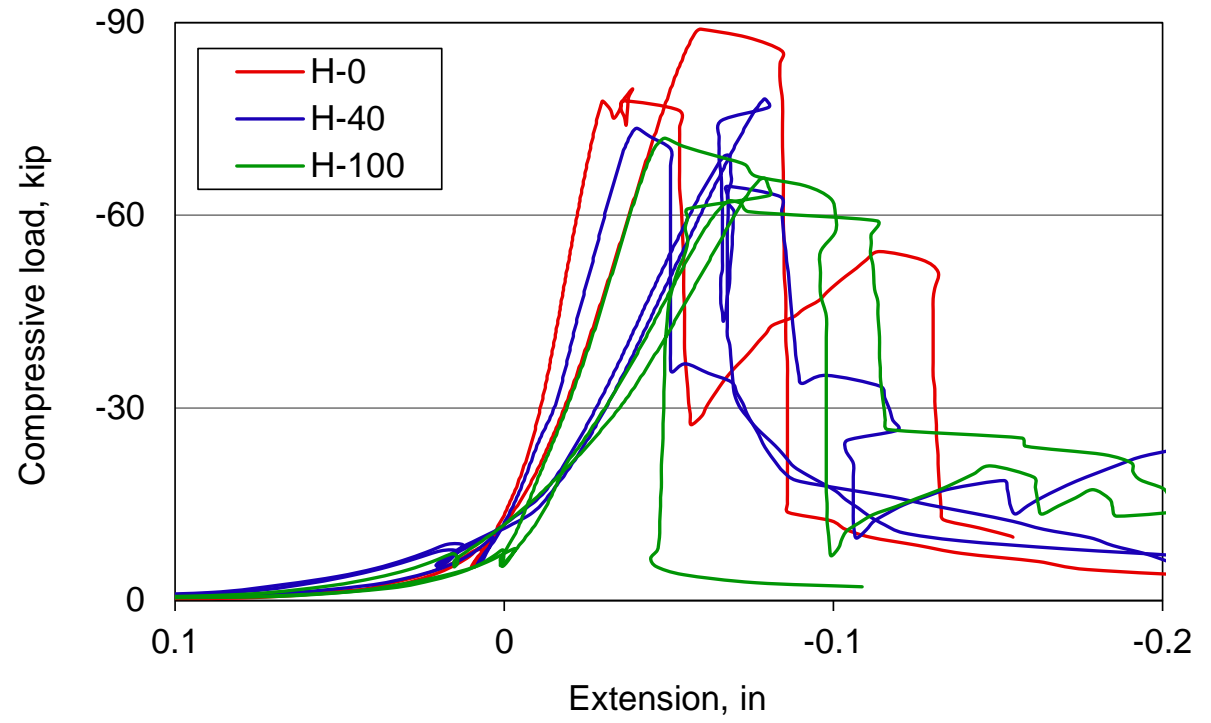

Figure 7. Load vs. displacement results for the compression testing of high-strength concrete specimens. 


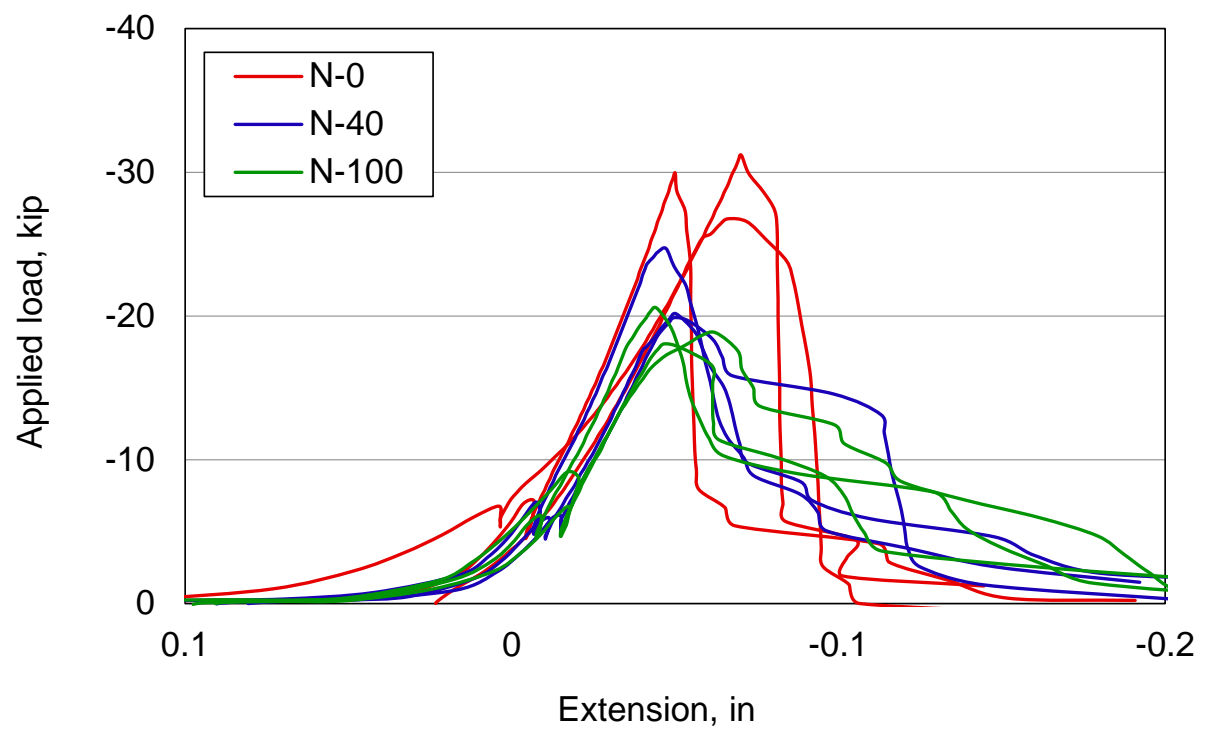

Figure 8. Load vs. displacement results for the splitting tensile strength testing of normal-strength concrete specimens.

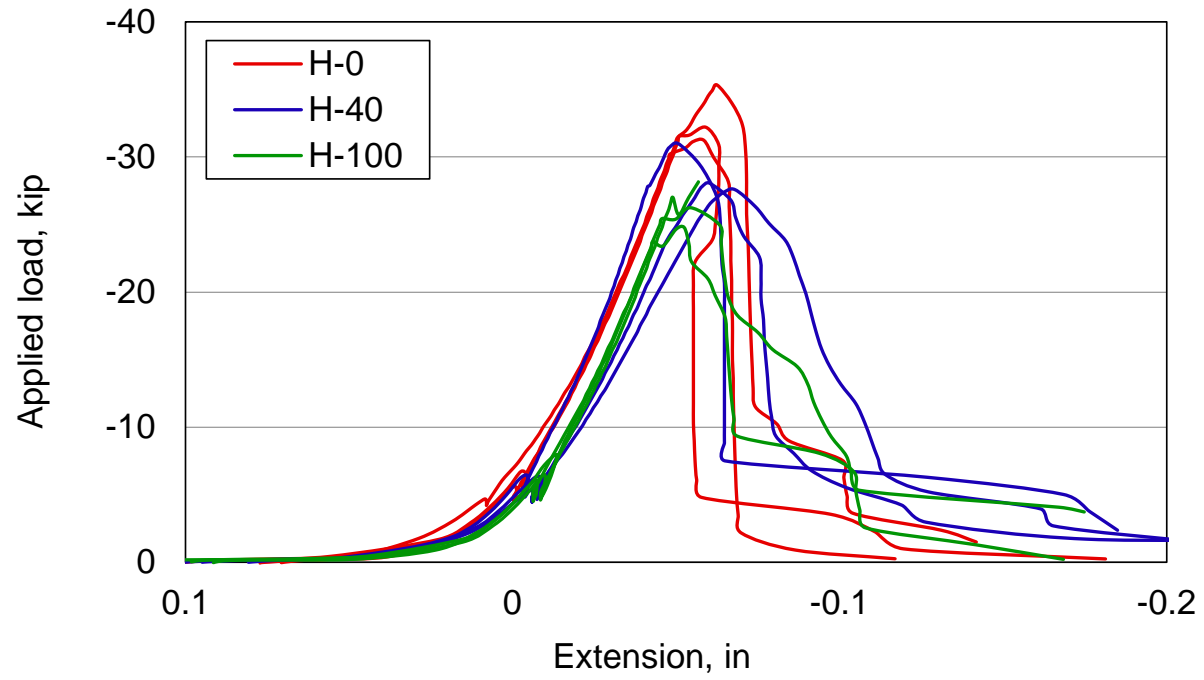

Figure 9. Load vs. displacement results for the splitting tensile strength testing of high-strength specimens. 


\section{Analysis of test data and discussion}

\subsection{Failure mechanism}

The failure of concrete specimens incorporating NA (N0, N40, H0 and H40) particularly the specimens with high strength concrete (H0 and H40) occurred mostly due to the cracks that grew through the NAs. In FRP-RA-incorporated specimens, cracks rarely passed through FRPRAs, but rather through the ITZ between FRP-RA and mortar, and through NAs if available in the specimens. The bond failure of FRP-RA incorporated compression specimens can be observed in Figure 4 (b, c, e, and f). The failure of NAs are clearly observed in splitting tension specimens in Figure 5 (a, b, d, and e); the NAs that are split have an exposed and non-dusty surface. The rounder shape and smoother surface of FRP-RAs (compared to NAs) particularly in the cut surface is the cause of bond failure in FRP-RA incorporated specimens.

\subsection{Strength}

The results show that incorporation of FRP-RA in concrete causes a reduction in the average compressive and the average splitting tensile strengths of concrete (Table 5). It is postulated that this is due to the better bond between mortar and NA than between mortar and FRP-RA. NA particles have angular shapes and rough surfaces and therefore maintain a good physical bond with the mortar in the concrete. Aggregates with round shape and smoother surface (such as river gravel, or FRP-RA in this study), even if prepared with the same size gradation as crushed stone, maintain a relatively weak bond with the mortar matrix [13]. Moreover, only six different sizes of FRP-RA were used as aggregate in the concrete (Figure 1.b), while the gradation of NA was gradual, which combined with the angular shape of the NA particles can enhance the interlock between the aggregates. 
An interesting observation is that the impact of replacing NA with FRP-RA is the same in both normal-strength and high-strength concretes; $13 \%$ and 21\% reduction in compressive strength for $40 \%$ and $100 \%$ replacement ratios respectively (Table 5). However, the impact of replacing NA with FRP-RA on splitting tensile strength is higher in normal-strength concrete; $25 \%$ and $35 \%$ reduction for $\mathrm{N} 40$ and $\mathrm{N} 100$ concretes, compared to $11 \%$ and $20 \%$ reduction for H40 and H100, respectively. Typically, the bond strength in the ITZ of a concrete with a strong mortar (matrix material) is expected to be higher than that of a concrete with the same coarse aggregate content and gradation but a weaker mortar. The reason is that the former has more cement content and more cement hydration materials (including Calcium-Silicate-Hydrate (C-SH)) are available to fill the voids in the ITZ zone. This can be observed in Figure 4 (a) and (d) (N0 and H0) and in Figure 4 (c) and (f) (N100 and H100); in both pairs, the coarse aggregates (either NA or FRP-RA) are better bonded to the mortar in high strength concrete. It is hypothesized that bond strength in the ITZ affects the tensile strength of concrete more than the compressive strength. During compressive loading, while shear stresses contribute to the disintegration of the concrete, the compressive stresses cause the mortar and coarse aggregates into contact with each other, reducing the effect of bond strength in the initiation of cracks in the ITZ. During tensile loading however, coarse aggregates and mortar are pulled apart and a weak bond can promote the failure.

The findings of this study, as presented in Figure 10, show that the ACI model safely predicted the splitting strength of "H" concretes. Although the predictions of the Eurocode model are very close to the splitting strength test results for " $\mathrm{H}$ " concretes, the Eurocode model overestimates the splitting tensile strength of $\mathrm{H} 100$ concrete. Both models over-estimated the tensile strength of FRP-RA incorporated "N" concretes. The existing models used in design are 
empirical equations obtained by the regression analysis of large data sets from testing concrete with aggregates of different shapes and surface textures. Therefore, as shown by the results of this study, these models do not account for the effect of aggregate type and shape on the ITZ bond strength. When new types of aggregate, particularly recycled aggregates, are used in structural concrete special attention should be given to the fact that compressive strength of concrete alone is not sufficient to find other mechanical properties of concrete used in design and these properties may have a larger impact on the behavior of the concrete than assumed.

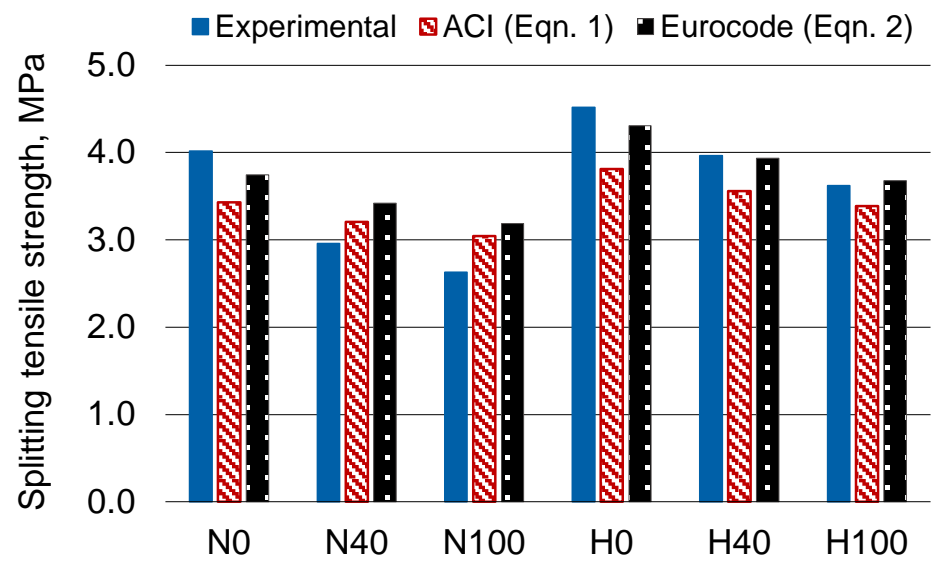

Figure 10. Splitting tensile strength of concrete from different mixes obtained by testing and theoretical models.

\section{Guidance for future research}

Numerous research studies have been performed in the past showing the ingress of aqueous solutions with chemicals such as chlorides and sulfates, and even the ingress of pure water, in FRP rebars can lead to gradual degradation of the glass fibers thereby affecting the durability and long-term mechanical performance of GFRP-rebar-incorporated concrete (readers 
can refer to $[14,15]$ for some pioneering studies and to $[16,17]$ for reviews on this topic).

Despite these findings there has been a continuous growth in the use of GFRP rebars in concrete mainly because in real-life (vs. laboratory) the resin coat on the lateral surface of the rebars can sufficiently protect the glass fibers. The cut ends of the rebars, if not sealed, can quickly absorb the surrounding moisture due to the capillary pressure caused by the voids between the fibers; a phenomenon known as wicking. This is not critical when GFRP rebars are used as continuous longitudinal or shear reinforcement since in concrete only few centimeters of rebar ends may degrade due to the ingress of moisture. Since FRP-RAs are short the entire FRP aggregate may become saturated and eventually degraded. Mechanical performance tests should be performed on FRP-RA-incorporated concretes exposed for a long period of time to water and different aqueous solutions replicating severe environmental conditions.

Another durability issue that should be investigated is the potential deterioration of FRPRA-mortar interface bond in concrete experiencing significant fluctuation in daily temperature or freeze-thaw cycles. The coefficient of thermal expansion (CTE) of cementitious mortar (18-20, $\left.10^{-6} /{ }^{\circ} \mathrm{C}[18]\right)$ is 65 to 100 times larger than the longitudinal CTE of GFRP $\left(0.18-0.31,10^{-6} /{ }^{\circ} \mathrm{C}\right.$ [19]). Therefore, in regions with significant temperature fluctuation strain differentials at the interface can lead to the weakening of the bond and therefore the load carrying capacity of concrete. To study the impacts of thermal debonding, FRP-RA concrete specimens, stored in environmental chambers programed to replicate real-life (but accelerated) severe temperature changes, should be tested for mechanical performance. 
Although the findings of the presented study shows that FRP-RA can be used for producing concrete with desired strength, developing FRP coarse aggregates/inclusions that can enhance the mechanical performance of concrete will be valuable. One potential approach is to cut rebars into longer needle-shape elements. FRP needles may enhance strength, toughness, and impact resistance. The authors have recently embarked on an experimental study about using FRP needles in concrete. The needles may also be a better option in terms of durability as they have a higher aspect ratio and therefore a low cut surface to total surface ratio; since moisture ingresses into rebars mainly from the cut ends, the needles are better protected from moisture. Findings of a preliminary study by the authors shows that longer cut GFRP rebars become saturated with a slower rate when immersed in water (Figure 11). In the preliminary study cut rebars with diameters of $6 \mathrm{~mm}$ and $19 \mathrm{~mm}$ and lengths ranging from $5 \mathrm{~mm}$ to $100 \mathrm{~mm}$ were oven-dried for a period of two weeks at the temperature of $58^{\circ} \mathrm{C}$ (below the temperature at which GFRP degrades). Approximately 200 grams of the cut bars of each size group were immersed in water at a temperature of $40^{\circ} \mathrm{C}$ (to replicate a hot environment). In Figure 11 the tested rebars are given the notation "R-diameter-length”. For example, R-6-100 represents rebars with the diameter of $6 \mathrm{~mm}$ and length of $100 \mathrm{~mm}$. After different periods of time the rebars were removed from the water, towel dried as described in ASTM C127, weighted, and re-immersed in water. The results presented in Figure 11 may not be very precise since (1) it is difficult to properly towel dry the surface of sand coated rebars, and (2) although as much as possible of the sand coating was removed from the surface of the rebars before testing, some of the sand was released during the two weeks of testing. However, the results clearly show that the saturation rate of longer rebars is significantly slower than that of the shorter rebars. 


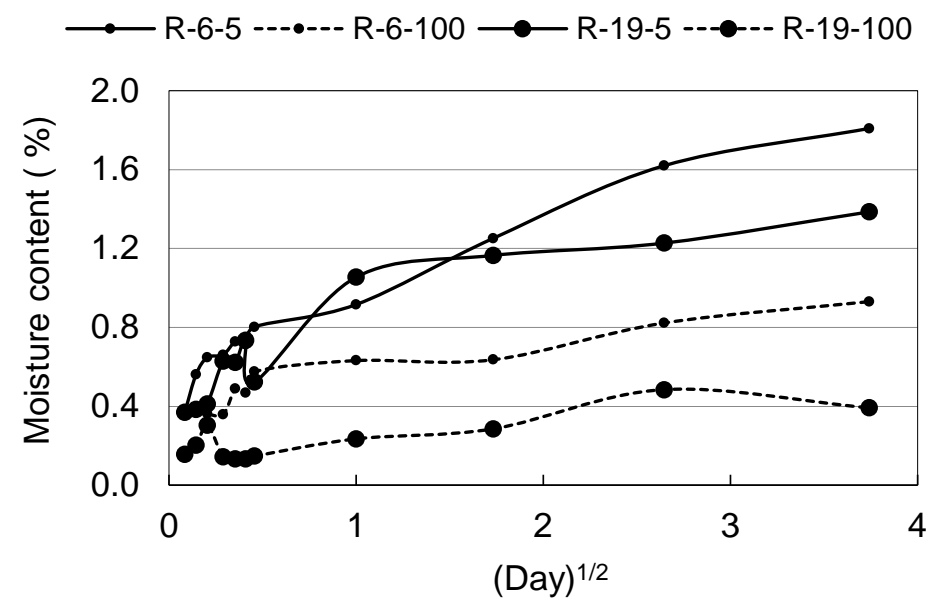

Figure 11. Moisture content of oven-dry cut rebars immersed in water over a period of two weeks. The results are for rebars with diameters of $6 \mathrm{~mm}$ and $19 \mathrm{~mm}$ and with lengths of $5 \mathrm{~mm}$ and $100 \mathrm{~mm}$.

Sustainable development is a major motivation for the use of recycled waste materials in concrete. However, although the reuse of waste leads to reduction in the consumption of natural resources and the size of landfills, it is not necessarily always a sustainable option. The incorporation of some waste materials in concrete results in the reduction in compressive strength which may be compensated by using additional cement [20] leading to increased $\mathrm{CO}_{2}$ emission. Life cycle assessment (LCA) studies should be performed to compare the environmental impacts caused by production of alternative concretes with and without processed FRP wastes, which have similar mechanical properties and durability.

\section{Summary and conclusions}

The summary of the findings and some important conclusions are listed below:

- The full replacement of NA with FRP-RA in the two types of concrete reduced the compressive strength of concrete by up to $21 \%$, and reduced the tensile strength of concrete by up to $35 \%$. 
- The lower compressive and tensile strength of FRP-RA concrete appears to be due to the weak bond between cut rebars and mortar. A waste processing technique that leads to FRPRAs with rougher surface, more angular shape, and more gradual size gradation can mitigate this issue.

- The existing ACI and Eurocode models cannot safely predict the splitting tensile strength of FRP-RA concrete. These empirical models should be calibrated. Alternatively, fundamental science-based models should be developed for predicting the tensile strength of concrete.

- Before using new types of aggregate with shapes and surface textures different from natural aggregate, the impact of the aggregates on all mechanical properties of concrete used in design of concrete structures, and not only on compressive strength, should be investigated.

- Although replacing NA with FRP-RA (100\% and 40\%) in concrete causes a significant reduction in the compressive and tensile strength, concrete with structural grade mechanical properties can be produced with RFP-RA. The effect of FRP-RA with different shapes and lower replacement ratios on the mechanical properties of concrete should be investigated.

- Experimental studies should be performed to compare the durability of concretes incorporating FRP waste and those with conventional coarse aggregate.

\section{Acknowledgement}

The authors wish to thank Mr. Doug Gremel from Hughes Brothers, Inc. for providing the FRP reinforcing bar production waste and technical information. The support of the US National Science Foundation (NSF) under Grant no. 1345379 is acknowledged. 


\section{References}

[1] Reynolds N, Pharaoh M. An introduction to composites recycling. In: Goodship V, editor. Management, Recycling and Reuse of Waste Composites: Woodhead Publishing; 2010. p. 3-19.

[2] Yazdanbakhsh A, Bank L. A critical review of research on reuse of mechanically recycled FRP production and end-of-life waste for construction. Polymers. 2014;6(6):1810-26.

[3] Asmatulu E, Twomey J, Overcash M. Evaluation of recycling efforts of aircraft companies in Wichita. Resources, Conservation and Recycling. 2013;80:36-45.

[4] Ribeiro MCS, Meira-Castro AC, Silva FG, Santos J, Meixedo JP, Fiúza A, et al. Re-use assessment of thermoset composite wastes as aggregate and filler replacement for concretepolymer composite materials: A case study regarding GFRP pultrusion wastes. Resources, Conservation and Recycling.

[5] Shahria Alam M, Slater E, Muntasir Billah A. Green concrete made with RCA and FRP scrap aggregate: fresh and hardened properties. J Mater Civ Eng. 2013;25(12):1783-94.

[6] Ogi K, Shinoda T, Mizui M. Strength in concrete reinforced with recycled CFRP pieces. Compos Part A: Appl Sci Manuf. 2005;36(7):893-902.

[7] ASTM C33/C33M, 2013, Standard specification for concrete aggregates. ASTM International, West Conshohocken, PA, USA.2013.

[8] ASTM C39/C39M-15a, 2015, Standard Test Method for Compressive Strength of Cylindrical Concrete Specimens. ASTM International, West Conshohocken, PA, USA.

[9] ASTM C496/C496M-11. Standard test method for splitting tensile strength of cylindrical concrete specimens. ASTM International, West Conshohocken, PA, USA. 2011.

[10] Building Code Requirements for Structural Concrete (ACI 318-14) and Commentary. Farmington Hills, MI: American Concrete Institute; 2014. 
[11] ENV 1992-1-1: Eurocode 2 - Design of concrete structures. Comité Européen de Normalisation (CEN); Brussels, Belgium 2008.

[12] ASTM C1231/C1231M-14, 2014, Standard test method for compressive strength of cylindrical concrete specimens. ASTM International, West Conshohocken, PA, USA.

[13] Rocco CG, Elices M. Effect of aggregate shape on the mechanical properties of a simple concrete. Eng Fract Mech. 2009;76(2):286-98.

[14] Fares ET, Hamid S. Environmental Effects on the Mechanical Properties of E-Glass FRP Rebars. ACI Mater J. 1998;95(2).

[15] Bank L, Puterman M. Microscopic study of surface degradation of glass fiber-reinforced polymer rods embedded in concrete castings subjected to environmental conditioning. In: Gates T, Zureick A-H, editors. High temperature and environmental effects on polymeric composites: 2nd volume, ASTM STP 1302: American Society for Testing and Materials; 1997. p. 191-205. [16] Grammatikos SA, Evernden M, Mitchels J, Zafari B, Mottram JT, Papanicolaou GC. On the response to hygrothermal aging of pultruded FRPs used in the civil engineering sector. Materials \& Design. 2016;96:283-95.

[17] ACI 440.9R-15 Guide to Accelerated Conditioning Protocols for Durability Assessment of Internal and External Fiber-Reinforce. American Concrete Institute, Farmington Hills, MI. 2015. [18] Mindess S, Young JF, Darwin D. Concrete. Second ed. Englewood Cliff, NJ: Prentice Hall; 2003.

[19] Nanni A, Luca AD, Jawaherizadeh H. Reinforced concrete with FRP bars, mechanics and design: CRC Press; 2014. 
[20] Yazdanbakhsh A, Bank L, Baez T, Wernick I, Hamidi A. A framework for life cycle assessment of concretes with recycled aggregates in large metropolitan areas. Sustainable Built Environment (SBE) Regional Conference, Zurich, June 15-17, 2016. 